Full Length Article

\title{
Developing, implementing and evaluating a simulation learning package on post-partum haemorrhage for undergraduate midwifery students in KwaZulu-Natal ${ }^{\text {is }}$
}

\author{
Hafaza Bibi Amod*, Petra Brysiewicz \\ Discipline of Nursing, School of Nursing \& Public Health, University of KwaZulu-Natal, Durban, South Africa
}

\section{A R T I C L E I N F O}

Article history:

Received 8 June 2016

Accepted 8 November 2016

Keywords:

KwaZulu-Natal

Learning package

Midwifery students

Simulation

\begin{abstract}
A B S T R A C T
Background: The training of undergraduate midwifery students to identify and manage post-partum haemorrhage, is an essential skill in midwifery.

Aim: The aim of this study was to develop, implement and evaluate a simulation learning package (SLP) on post-partum haemorrhage for undergraduate midwifery students using high fidelity simulation without risks to real-life patients.

Methods: An exploratory sequential mixed methodology was used in this study. The study was made up of three phases namely; the development, implementation and evaluation of the learning package. The research participants were fourth year baccalaureate of nursing midwifery students and midwifery experts involved in teaching midwifery. Data was collected using an evaluation checklist for experts, a student satisfaction survey and focus group sessions. Quantitative data were analysed using SPSS Version 23.0 and the qualitative data was analysed using content analysis as described by Graneheim and Lundman (2004).

Results: The evaluation checklist for experts revealed that the developed SLP was considered suitable for undergraduate students. It encouraged active learning, teamwork and accommodated diverse learning styles. The package was easy to use and offered opportunities for student feedback.

The student satisfaction survey revealed that the pre-simulation support received was adequate and helpful, and the post simulation outcomes showed that using high fidelity simulation improved clinical skills, knowledge, critical thinking, self-confidence and satisfaction.

The focus group sessions revealed that the SLP was an innovative and interactive method of learning; it improved the student's perception of their clinical competence, stimulated critical thinking and increased self-confidence.
\end{abstract}

\footnotetext{
Research significance: To develop a simulation learning package that uses high fidelity simulation to teach undergraduate midwifery students how to manage post-partum haemorrhage.

* Corresponding author.

E-mail address: Amodh@ukzn.ac.za (H.B. Amod).

Peer review under responsibility of Johannesburg University.

http://dx.doi.org/10.1016/j.hsag.2016.11.004

1025-9848/@ 2016 The Authors. Publishing services by Elsevier B.V. on behalf of Johannesburg University. This is an open access article under the CC BY-NC-ND license (http://creativecommons.org/licenses/by-nc-nd/4.0/).
} 
Conclusion: A simulation learning package, that uses high fidelity simulation, can be an innovative and interactive method to teach midwifery emergencies.

(C) 2016 The Authors. Publishing services by Elsevier B.V. on behalf of Johannesburg University. This is an open access article under the CC BY-NC-ND license (http:// creativecommons.org/licenses/by-nc-nd/4.0/).

\section{Introduction}

High Fidelity Human Patient Simulators (HFHPS) are computer-controlled mannequins which allow students to interact with an 'almost real' patient in a realistic way (Bearnson \& Wiker, 2005). The HFHPS respond to clinical interventions that are carried out in a realistic way, thus providing a safe and authentic learning environment and alleviating the growing fears and concerns relating to patient safety during students learning experience (Nevin, Neill, \& Mulkerrins, 2014). Valadares and Magro (2014) agree that simulation provides an opportunity for students to practice and correct their mistakes in a clinical situation, without risks to patients and with minimal risk to themselves. Parker and Myrick (2009) add that the integration of high fidelity simulation into the curriculum can be a powerful learning tool in the integration of knowledge, skills and attitudes of students.

Obstetrics is a high risk unit where emergencies arise unexpectedly. According to the recent Saving Mothers Report (2011-2013), post-partum haemorrhage was the third most common cause of maternal mortality in South Africa and accounted for 25 per cent of maternal deaths worldwide. The report concluded that a number of the deaths were avoidable and highlighted that health care providers were doing too little, too late.

Obstetric emergencies are multifaceted and complex and their urgency demands a combination of clinical skills. As a result, very little teaching can be done during these emergency situations. In a randomised trial of simulation versus didactic teaching for obstetric emergencies, Daniels et al. (2010) showed that simulation trained teams had superior performance scores when tested in a labour and delivery drill, and therefore concluded that simulation should be used to enhance obstetrical emergency training. Reynolds, Ayres-de Campos, and Lobo (2011) found that health care professionals who had participated in a simulation based training course in obstetrical emergencies perceived a substantial improvement in their knowledge and skills when witnessing real life emergencies.

The management of obstetric emergencies in the midwifery curriculum is currently taught using problembased scenarios. According to Badeau (2010), problem-based scenarios are designed to challenge the learners to meet the curriculum objectives and therefore, introducing simulation training into the curriculum may enhance teaching and learning.

A simulation learning package (SLP) is a learning package that uses simulation to build and process discrete events and situations (Abu-Taieh \& El-Sheikh, 2010, p. 14). In this study, the SLP was a comprehensive learning package which consisted of learning objectives, pre-requisite knowledge, preparation for and participation in a role-play using the high fidelity computer-controlled mannequins.

At this local university, HFHPS are available for the training of medical and nursing students, but these mannequins have not been used to their full potential to date. The importance of developing this SLP was therefore to use this innovative technology more effectively to simulate a real-life situation, with the purpose of improving knowledge and skills in managing post-partum haemorrhage, and in so doing, highlight the versatility and true potential of this high fidelity equipment for midwifery training.

Although much research has been conducted relating to simulation training in nursing, such as the studies by Jeffries (2007), Blum, Borglund, and Parcells (2010), and Khailala (2014), limited research has been done using high fidelity simulation within the midwifery curriculum in South Africa.

\section{Aim of the study}

The aim of this study was to develop, implement and evaluate a simulation learning package on post-partum haemorrhage for undergraduate midwifery students using high fidelity simulation.

\section{Research objectives}

1. To develop a simulation learning package on post-partum haemorrhage for undergraduate midwifery students;

2. To implement the simulation learning package for a group of midwifery students;

3. To evaluate the simulation learning package on postpartum haemorrhage.

\section{Research design}

An exploratory, sequential mixed methodology as described by Creswell and Clark (2010) was chosen for this three phase study, underpinned by the Nursing Education Simulation Framework cited by Jeffries (2007). The SLP was carefully developed and submitted to experts for evaluation purposes. The SLP was then implemented in phase 2 and concluded with the evaluation of the SLP in phase 3 of the study. 


\subsection{Research setting}

The research setting was a university within the province of KwaZulu-Natal, South Africa. The nursing school has a clinical skills laboratory where low, medium and high fidelity simulators are available for use to nursing students within the undergraduate and postgraduate programmes.

\subsection{Research participants}

These included all fourth year undergraduate students registered for the midwifery module in 2015 , as well as a group of midwifery experts who were used to evaluate the SLP. These experts needed to have a minimum of two years' experience in midwifery or obstetric education and included nurse educators from universities and colleges of nursing.

\subsection{Data collection process}

In Phase One, the simulation learning package was developed following an extensive literature search on simulation scenario development toolkits and various best practice guidelines for the management of postpartum haemorrhage using different databases.

The Californian Toolkit (Gabel \& Weeber, 2012) for scenario development was selected as the guideline to develop this learning package, and integrated the South African National Department of Health and World Health Organization guidelines on postpartum haemorrhage.

The package included the learning objectives, pre-requisite readings, pre-simulation preparation, a simulation design process, the roles of participants in the simulation and a debriefing process. Once drafted, the learning package was hand delivered by the researcher to the ten (10) midwifery experts from various South African colleges and universities. The completed evaluation forms were collected two weeks later.

In Phase Two, the SLP was introduced to a group of undergraduate midwifery students. Students were given the prerequisite requirements in the class, a month before the simulation session. A lecture on post-partum haemorrhage was presented in class and students were then given time to practice their newly acquired skills in the clinical skills laboratory, using the HFHPS (SimMom).

On the morning of the simulation implementation, students were asked to volunteer to participate in the simulation session. All students were very enthusiastic and excited to be involved in the simulation scenario. Two groups of six students each participated in the simulation session. Their roles included that of a unit manager, a senior midwife, a junior midwife, a staff nurse, a doctor and a husband (birth companion). The simulation session was video-recorded with the permission of the participants, and these participants were observed throughout the simulation session. A research assistant, two laboratory assistants and a technician were available to assist in the implementation phase. During this phase, the team performance was evaluated against assessment guidelines on the management of Post-partum haemorrhage. A debriefing session which allowed for feedback opportunities was conducted by the researcher and the research assistant, and this concluded the implementation phase.

In Phase three, all students $(\mathrm{N}=43)$ were required to complete a Student Satisfaction Survey. The aim of the survey was to assess the pre-simulation support that was received and the post simulation learning outcomes that were achieved.

Two single focus group sessions (Morgan, 1996) were conducted to allow participants to describe their experience following the simulation session. The first focus group session which consisted of 12 students (role-players) was conducted on the same day in the skills laboratory. A second focus group session was conducted two weeks later in the clinical facility with 8 students who participated as either role-players or observers of the simulation session. A total of 20 students participated in the focus group sessions. Both focus group sessions were audio recorded and data saturation was achieved in the second session when no new information was obtained.

\subsection{Data collection tools}

The Evaluation Checklist for Experts was used to evaluate the SLP on post-partum haemorrhage. Permission to use and adapt the tool was obtained from the author (Scriven, 2011) via email correspondence. The tool was adapted to suit the research questions and a section for additional comments was added.

The Student Satisfaction Survey was developed by Nevin et al. (2014). Permission to use and amend the tool was obtained from the authors. The amendments included the addition of Section B, which consisted of two open-ended questions.

Two focus group sessions were conducted. The first session was conducted on the same day following the simulation session. A second focus group session was conducted two weeks later as a means to identify whether students were able to apply their skills learnt during the simulation experience.

\subsection{Data analysis}

Quantitative data was analysed using SPSS Version 23.0 and the results of the open-ended questions and the focus group sessions were analysed using content analysis (Graneheim \& Lundman, 2004).

\section{Results}

\subsection{Development of the SLP}

A total of sixteen experts were invited to participate in this study. All experts responded, however only ten agreed to participate in the study.

The results of the checklist showed that the quality of the contents of the SLP on post-partum haemorrhage was found to be appropriate, clear, current, relevant and accurate for undergraduate midwifery students. The SLP package incorporated active learning methods, promoted collaboration and high expectations, and incorporated diverse learning styles. It 
was also found to be user friendly and offered feedback opportunities. The results also showed that some experts evaluated the SLP as fair in terms of the accuracy and the currency of the information, as well as for the presentation and feedback opportunities. Table 1 shows the results of the evaluation checklist.

Most of the comments received from experts were valuable in improving the package and were thus accepted. Once the amendments were made, a practice run was scheduled and conducted with the clinical specialists. The aim of the practice run was to ensure that the simulation setup resembled a labour/delivery suite similar to that in the clinical setting. Feedback from the clinical specialists regarding practical issues was considered and the simulation learning package was further amended.

\subsection{Implementation of the SLP}

During this phase, students were excited to participate using a high fidelity simulation, as it allowed them to be 'hands on'. Two teams of 6 students each participated in the simulation session. The team performance was evaluated according to assessment guidelines in the management of PPH. Both teams felt more prepared in identifying and managing postpartum haemorrhage as an obstetric emergency. This session highlighted their improved clinical competence, teamwork, decision making and critical thinking skills in an emergency situation.

\subsection{Simulation evaluation}

A total of forty three students were asked to evaluate the SLP using a Student Satisfaction Survey and by participating in a focus group discussion. Section A of the survey evaluated the pre-simulation support and the post simulation outcomes. Table 2 shows the results of the Student Satisfaction Survey.

\subsection{The pre-simulation support}

The results from the pre-simulation support showed that 42 participants agreed that the support material they received was well structured and prepared them for the session, 39 students agreed that the support material was easy to follow and 35 participants were in agreement that the websites accessed before attending the session adequately prepared them for participating in the simulation session. The findings regarding the need for more support in preparation for the simulation session showed that 13 participants agreed that they needed more support, 11 participants were unsure and the remaining 19 participants disagreed with the statement, stating that they had not needed further pre-simulation support. A third of the total student population who participated in this study thus stated that more pre-simulation support was needed.

\subsection{Post-simulation outcomes}

The post-simulation outcome results revealed that most participants agreed that the simulation process was helpful for understanding the core clinical skills required when managing a critically ill patient, tested their knowledge to an appropriate level of nursing care, allowed them to demonstrate clinical decision making skills, and they were confident that they would use the knowledge gained from this simulation session in clinical practice. All participants agreed that they were satisfied with the simulation session. The comments from Section B indicated that the use of high fidelity simulation was beneficial to student midwives and should be used at other levels of the nursing programme.

\subsection{The focus group sessions}

Two focus group sessions were conducted with the students. The first group included students who were directly involved in the simulation scenario on post-partum haemorrhage, and the second group included students who were observers of the

Table 1 - Expert's responses to the evaluation checklist $(n=10)$.

\begin{tabular}{|c|c|c|c|c|}
\hline Criteria & $\begin{array}{c}\text { Fair } \\
\text { (n) }\end{array}$ & $\begin{array}{l}\text { Good } \\
(\mathrm{n})\end{array}$ & $\begin{array}{l}\text { Excellent } \\
\text { (n) }\end{array}$ & Comments \\
\hline \multicolumn{5}{|c|}{ Quality of the contents of the SLP } \\
\hline Appropriate & 0 & 4 & 6 & \multirow{5}{*}{$\begin{array}{l}\text { An excellent learning package that is relevant and } \\
\text { appropriate for empowering students. Current and } \\
\text { innovative strategies are used }\end{array}$} \\
\hline Clear & 0 & 3 & 7 & \\
\hline Current & 1 & 1 & 8 & \\
\hline Relevant & 0 & 1 & 9 & \\
\hline Accurate & 2 & 0 & 8 & \\
\hline \multicolumn{5}{|c|}{ Effectiveness of the simulation learning package } \\
\hline Active learning practices & 0 & 3 & 7 & \multirow{4}{*}{$\begin{array}{l}\text { The package stimulate critical thinking and problem } \\
\text { solving skills for students. The outcomes will surely } \\
\text { produce 21st century innovative learners }\end{array}$} \\
\hline Promotes collaboration & 0 & 4 & 6 & \\
\hline $\begin{array}{l}\text { Uses diverse learning } \\
\text { styles }\end{array}$ & 0 & 3 & 7 & \\
\hline $\begin{array}{l}\text { Reflects high } \\
\text { expectations }\end{array}$ & 0 & 4 & 6 & \\
\hline \multicolumn{5}{|l|}{ Ease of use } \\
\hline Presentation & 1 & 3 & 6 & \multirow{2}{*}{$\begin{array}{l}\text { The package is well presented, user friendly and allows } \\
\text { for feedback }\end{array}$} \\
\hline Feedback opportunities & 1 & 2 & 7 & \\
\hline
\end{tabular}




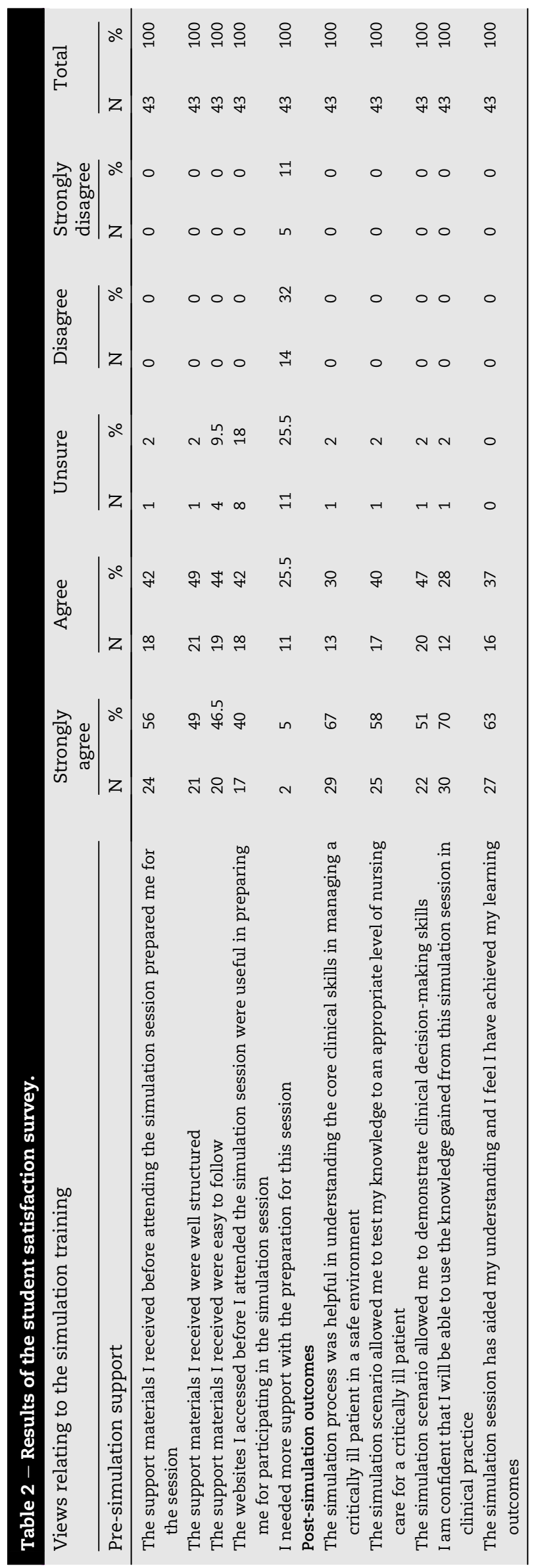

simulation. The following categories emerged from the focus group sessions and were similar for both groups.

\subsubsection{Simulation is an authentic and interactive teaching method which promotes teamwork}

The findings revealed that the students found high fidelity simulation to be an innovative way of learning. Students found that using SimMom added realness to the scenario and they were able to link the simulation to the clinical situation. One of the focus group participants said:

The SimMom responds like a real patient. You can speak to the SimMom and do [the] vital signs. You actually had to monitor the vital signs and not knowing what to expect added to the realness of the situation.

\section{Another participant said}

This is a new method of learning. We were excited to be actively involved in the team in managing post-partum haemorrhage.

Another student added

The setup was real, like being in a labour ward.

\subsubsection{Simulation improves clinical competence}

Role-playing in an obstetric emergency scenario can be very challenging for students as the expectations of their performance are extremely high. A student who was involved in the role play stated:

For me, when there are obstetric emergencies in the ward I usually panic. Now with $\mathrm{PPH}$... because we did the whole simulation thing, I know what to do more than I would for any other obstetric emergency.

\section{Another student commented:}

After the simulation scenario I can recall what I saw them doing and will be able to link this to the clinical setting.

\subsubsection{Simulation increases self-confidence and stimulates} critical thinking skills

The findings of this study showed that an increase in selfconfidence was achieved and this can be observed in the comments given by the participants. One role-player commented:

After the simulation, we had a patient and I was really able to help because I knew what to do and this boosted my confidence.

Another student stated:

I had to think quick[ly] on my feet. With SimMom you were able to check the patient's condition and vital signs and, depending on your findings, you needed to think what to do next.

A third student commented: 
We were able to pick up what went well or what went wrong and what was not done. And then we were able to evaluate ourselves and the team members as well.

Participating in the simulations provided invaluable clinical experience for these midwifery students as it allowed them to overcome their lack of actual clinical involvement.

\section{Ethical considerations}

The following ethical considerations of anonymity, confidentiality and informed consent as described by Burns and Grove (1993) were applied in this study. Participants were informed of their right to voluntary participation and their right to withdraw at any time. Participant were informed that all data obtained, analysed and interpreted would be anonymised and kept securely. An information sheet explaining the purpose and nature of the study was issued to each participant prior to obtaining their written consent. There were no risks associated with participation in this study and it did not affect their educational programme in any way. Permission was granted to conduct this research by the Registrar for Health Sciences and the Humanities and by the Social Sciences Research Ethics Committee (HSS/0320/015M).

\section{Rigor}

\subsection{Quantitative data}

Two quantitative evaluation tools were used in this study, namely the Evaluation Checklist for Experts and the Student Satisfaction Survey. Both instruments were previously used in similar studies done by Nevin et al. (2014); Hallmark, Thomas, and Gantt (2014); Groom, Henderson, and Sittner (2014). The Cronbach co-efficient alpha scores for both these tools ranged between 0.7 and 0.96. Permission to use and adapt the tools was granted from the authors via email correspondence. A pilot study was also conducted with clinical specialists and the feedback received was used to make minor amendments to the package.

\subsection{Qualitative data}

The researcher was guided by the 4 principles of trustworthiness as addressed by Lincoln and Guba (1985). In this study, the credibility was achieved by the prolonged relationship with the participants. These students had been in contact with one of the researchers and thus had a good rapport with her. Participants were encouraged to speak freely in order to express their views regarding the research. All data were analysed with the guidance of the research supervisor, who is a more experienced qualitative researcher. Frequent debriefing sessions were held to ensure the accurate interpretations of the data and details were provided to give the reader a sense of the path taken. Regarding the dependability of the study, the researchers attempted to describe the decision-making processes of the study as well as the context. Concerning transferability, the researchers attempted to provide sufficient information to allow the reader to decide if this study findings can be transferred to their own setting. Confirmability was concerned with giving the reader an indepth description of the research, to give the reader a sense of 'being there' and thus allow them to follow the research path and see how the conclusions of the study were arrived at.

\section{Discussions}

The SLP package was found to be suitable for undergraduate midwifery students as it contained essential design characteristics such as active learning, teamwork, diverse learning strategies and opportunities for feedback. In a study done by Smith and Roehrs (2009), the design characteristics, especially the clear learning objectives, were significantly correlated with student satisfaction and self-confidence. These characteristics, as well as clinical competence and critical thinking, were similar to the outcomes of this current study.

An integrative review done by La Fond and Vincent (2012) identified 16 publications that used the same framework as that used in this study, thus proving the value of this framework. La Fond and Vincent (2012) showed increased student satisfaction, confidence, and improved skills performance by using simulation as a training tool. A systematic review by Adamson (2015) of 153 studies provided empirical support for the major components of the NLN/Jeffries Simulation Framework and contributed to the further development of this framework. Similar support was also seen in a study done by Hallmark et al. (2014).

While implementing the SLP, students found the simulation experience to be exciting. They found that being actively involved in an emergency situation augmented the urgency of the situation. They were satisfied that their patient recovered well and the positive experience boosted their confidence levels. The outcomes of this study support the findings of Butler, Veltre, and Brady (2009), who also demonstrated the value of simulation in creating active learning opportunities and supporting best practices in the undergraduate education programmes. In a study done by Bambini, Washburn, and Perkins (2009), findings revealed that nursing students experienced an increase in self-efficacy and confidence as a result of simulation, and learned that communication and prioritising patient care were important aspects in simulation. Burns, O'Donnell and Artman (2010) showed that 82 per cent of the students that participated in their study gained additional knowledge, and all students showed positive differences for outcomes such as critical thinking, confidence and communication.

When evaluating the SLP, the students found the simulation experience to be innovative. Participation promoted teamwork, improved their clinical competence, enhanced critical thinking abilities and increased their self-confidence. In a study conducted by Moule, Wilford, Sales, and Lockyer (2008), it was also reported that students demonstrated an increase in knowledge, skills and self-confidence, and these authors recommended that simulations be incorporated into the curriculum. In more recent studies, Valadares and Magro (2014); Nevin et al. (2014); Mikasa, Cicero, and Adamson 
(2013); Sundler, Petterson, and Berglund (2015) obtained similar findings.

Many researchers have been concerned about learner satisfaction related to higher student performance levels (Jeffries, 2007). Blum et al. (2010); Alfes (2011); Mould, White, and Gallagher (2011); Khailala (2014) allayed these concerns regarding the level of satisfaction when they demonstrated that student nurses experienced higher satisfaction levels when learning using high fidelity simulations.

\section{Limitations}

The limitations of this study were the small sample size used and the single research setting chosen. Another limitation was that the researcher was known to the participants and this could have influenced the students' performance.

\section{Recommendations}

Simulation learning appears to complement clinical training and if integrated into the curriculum, may improve current educational practices. Incorporating high fidelity simulation into the first year of nurse training may be beneficial to students.

Obstetrics is a high risk environment and the safety of the mother and the unborn child is imperative. Simulation provides an 'authentic', safe environment for the practice of these essential skills before attending to patients in the 'real' clinical setting.

Further research to support the enhanced use of simulation is required in order to develop more simulation packages that reflect emergency midwifery care. A number of different simulation learning packages should be available to teach nurses to deal with a multitude of clinical scenarios. The impact of simulation on clinical performance should also be further researched.

\section{Conclusion}

The integration of high fidelity simulation into the undergraduate curriculum allows students an opportunity to experience a real life situation in a safe learning environment. Simulation enhances practice and may therefore reduce the time taken to achieve clinical competence. There are many studies that recommend using simulation to enhance classroom teaching and as a method that complements clinical accompaniment. More research is needed to show how simulation contributes to clinical expertise.

\section{Author contribution}

The study was conceptualized, carried out and analyzed by both authors. HBA collected the data and PB was the research supervisor. Both authors drafted the manuscript.

\section{R E F E R E N C E S}

Abu-Taieh, E. M. O., \& El-Sheikh, A. A. (2010). Handbook of research on discrete event simulation environment: Technologies and Applications. New York: Hershey Publishers.

Adamson, K. (2015). A systematic review of the literature related to the NLN/Jeffries simulation framework. Nursing Education Perspectives, 36(5), 281-291.

Alfes, C. (2011). Evaluating the use of simulation with beginning nursing students. Journal of Nursing Education, 50(2), 89-93.

Badeau, K. A. (2010). Problem based learning: An educational method for nurses in clinical practice. Journal for Nurse in Staff Development, 26(6), 244-249.

Bambini, D., Washburn, J., \& Perkins, R. (2009). Outcomes of clinical simulation for novice nursing students:

Communication, confidence, clinical judgement. Nursing Education Perspectives, 30, 79-82.

Bearnson, C. S., \& Wiker, K. M. (2005). Human patient simulators: A new face in baccalaureate nursing education at Brigham Young University. Journal of Nursing Education, 44(9), 421-425.

Blum, C. A., Borglund, S., \& Parcells, D. (2010). High fidelity nursing simulation: Impact on student self-confidence and clinical competence. International Journal of Nursing Education Scholarship, 7(1), 1-14.

Burns, N., \& Grove, S. K. (1993). The practice of nursing research. Conduct, Critique \& Utilization, 4.

Burns, H. K., O'Donell, J., \& Artman, J. (2010). High fidelity simulation in teaching problem solving to 1st year nursing students. Clinical Simulation in Nursing, 6(3), 87-95.

Butler, K. W., Veltre, D. E., \& Brady, D. (2009). Implementation of active learning pedagogy comparing low-fidelity simulation versus high fidelity simulation in paediatric nursing education. Clinical Simulation in Nursing, 5(4), e129-e136.

Creswell, J. W., \& Clark, P. (2010). Designing and conducting mixed methods research (2nd ed.). Thousand Oaks: Sage Publishers Inc.

Daniels, K., Arafeh, J., Clark, A., Waller, S., Druzin, M., \& Chueh, J. (2010). Prospective randomized trial of simulation versus didactic teaching for obstetrical emergencies. Simulation in Health Care, 5(1), 40-45.

Gabel, K. T., \& Weeber, T. A. (2012). Measuring and communicating blood loss during obstetric haemorrhage. Journal of Obstetric, Gynecologic \& Neonatal Nursing, 41(4), $551-558$.

Graneheim, U. H., \& Lundman, B. (2004). Qualitative content analysis in nursing research: Concepts, procedures, and measures to achieve trustworthiness. Nurse Education Today, 24, 105-112.

Groom, J. A., Henderson, D., \& Sittner, B. (2014). NLN/Jeffries simulation framework state of the science project: Simulation design characteristics. Clinical Simulation in Nursing, 10(7), 337-344.

Hallmark, B. F., Thomas, C. N., \& Gantt, L. (2014). The educational practices construct of the NLN/Jeffries simulation framework: State of the science. Clinical Simulation in Nursing, 10(7), 345-352. https://cirt.gcu.edu/research/ developmentresources/research_ready/focus_groups/types.

Jeffries, P. R. (2007). Simulation in nursing education: From conceptualisation to evaluation. New York: National League for Nursing.

Khailala, R. (2014). Simulation in nursing education: An evaluation of students' outcomes at their first clinical practice combined with simulations. Nurse Education Today, 34(2), 252-258.

Lafond, C. M., \& Van Hulle Vincent, C. (2012). A critique of the national league for nursing/Jeffries simulation framework. Journal of Advanced Nursing, 1365-2648. 
Lincoln, Y. S., \& Guba, E. G. (1985). Naturalistic Inquiry. Newbury Park, CA: Sage Publications.

Mikasa, A. W., Cicero, T. F., \& Adamson, K. A. (2013). Outcomebased evaluation tool to evaluate student performance in high-fidelity simulation. Clinical Simulation in Nursing, 9(9), e361-e367.

Morgan, D. L. (1996). Focus groups as qualitative research. Sage Publications.

Mould, J., White, H., \& Gallagher, R. (2011). Evaluation of a critical care simulation series for undergraduate nursing students. Contemporary Nurse, 38(1-2), 180-190.

Moule, P., Wilford, A., Sales, R., \& Lockyer, L. (2008). Student experiences and mentor views of the use of simulation for learning. Nurse Education Today, 28(7), 790-797.

Nevin, M., Neill, F., \& Mulkerrins, J. (2014). Preparing the nursing student for internship in a pre-registration nursing program: Developing a problem based approach with the use of high fidelity simulation equipment. Nurse Education Practice, 14(2), 154-157.

Parker, B. C., \& Myrick, F. (2009). A critical examination of high fidelity human patient simulation within the context of nursing pedagogy. Nurse Education Today, 29(3), 322-329.
Reynolds, A., Ayres-de Campos, D., \& Lobo, M. (2011). Selfperceived impact of simulation based training on the management of real-life obstetrical emergencies. European Journal of Obstetrics \& Gynaecology and Reproduction Biology, 159(1), 72-79.

Saving Mothers. (2011-2013). Sixth Report on the confidential enquiries into maternal deaths in South Africa. (2013). Retrieved from: htpp//www.kznhealth.gov.za/savingmothers.

Scriven, M. (2011). Evaluating evaluations: A meta-evaluation checklist, Consultado em, 9.

Smith, S. J., \& Roehrs, C. J. (2009). High-fidelity simulation: Factors correlated with nursing student satisfaction and selfconfidence. Nursing Education Perspectives, 30(2), 74-78.

Sundler, A. J., Petterson, A., \& Berglund, M. (2015). Undergraduate nursing students' experience when examining nursing skills in clinical simulation laboratories with high fidelity patient simulators: A phenomenological research study. Nurse Education Today, 34(12), 1257-1261.

Valadares, A. F., \& Magro, M. C. (2014). Opinions of nursing students on realistic simulation and the curriculum internship in hospital setting. Acta Paulista de Enfermagem, 27, 138-143. 